\title{
The Dynamin 2 inhibitor Dynasore affects the actin filament distribution during mouse early embryo development
}

\author{
Qiao-Chu WANG'1), Jun LIU1), Xing DUAN1), Xiang-Shun CUI 2), Nam-Hyung KIM²), \\ Bo XIONG ${ }^{1)}$ and Shao-Chen SUN ${ }^{1)}$
}

\author{
${ }^{1)}$ College of Animal Science and Technology, Nanjing Agricultural University, Nanjing 210095, China \\ ${ }^{2)}$ Department of Animal Sciences, Chungbuk National University, Chungbuk 361-763, Korea
}

\begin{abstract}
Dynamin 2 is a large GTPase notably involved in clathrin-mediated endocytosis, cell migration and cytokinesis in mitosis. Our previous study identified that Dynamin 2 regulated polar body extrusion in mammalian oocytes, but its roles in early embryo development, remain elusive. Here, we report the critical roles of Dynamin 2 in mouse early embryo development. Dynamin 2 accumulated at the periphery of the blastomere during embryonic development. When Dynamin 2 activity was inhibited by Dynasore, embryos failed to cleave to the 2-cell or 4-cell stage. Moreover, the actin filament distribution and relative amount were aberrant in the treatment group. Similar results were observed when embryos were cultured with Dynasore at the 8-cell stage; the embryos failed to undergo compaction and develop to the morula stage, indicating a role of Dynamin 2 in embryo cytokinesis. Therefore, our data indicate that Dynamin 2 might participate in the early embryonic development through an actin-based cytokinesis.
\end{abstract}

Key words: Actin filament, Cytokinesis, Dynamin, Embryo

(J. Reprod. Dev. 61: 49-53, 2015)

D ynamin has been known for its molecular motor-like properties [1]. Dynamin is a large multi-domain GTPase involved in diverse cellular processes, especially in clathrin-mediated endocytosis [2], cell migration [3] and cell division [4]. In mammals, there are three classical isoforms: Dynamin 1, Dynamin 2 and Dynamin 3. Different from Dynamin 1 and Dynamin 3, which are expressed in a tissue-specific manner, Dynamin 2 exhibits an ubiquitous expression $[5,6]$. Structurally, a GTPase domain, a middle domain, a pleckstrin homology (PH) domain, a GTPase effector domain (GED) and a proline-rich domain (PRD) comprise the Dynamin 2 [7]. In addition to its critical roles in endocytosis, Dynamin 2 also binds with several proteins, such as Cortactin, Profilin, and Syndapin,to regulate the actin filaments [8-10].

Actin filaments exist in two forms in cells, the globular monomer (G-actin) or filamentous F-actin. The actin cytoskeleton is involved in cellular morphogenesis, motility, division, intracellular transport and other cellular processes [11]. Plenty of work has shown that actin dynamics are closely regulated by the actin regulatory proteins [12-14].

The mammalian embryo development process involves cell division, cell differentiation and cellular morphogenesis. After sperm penetration, actin is responsible for spindle rotation and pronuclear apposition as well as the cleavage and polarity of embryos in different species [15]. Our previous evidence shows that Dynamin 2

Received: June 19, 2014

Accepted: October 17, 2014

Published online in J-STAGE: November 21, 2014

C2015 by the Society for Reproduction and Development

Correspondence: S-C Sun (e-mail: sunsc@njau.edu.cn)

This is an open-access article distributed under the terms of the Creative Commons Attribution Non-Commercial No Derivatives (by-nc-nd) License $<\mathrm{http}: / /$ creativecommons.org/licenses/by-nc-nd/3.0/>. plays an important role in oocyte maturation through an actin-based pathway [16]; however, whether Dynamin 2 participates in embryo development remains elusive. In the present study, we focused on the relationship between Dynamin 2 and actin dynamics during embryonic development. Our results indicate that the Dynamin 2 inhibitor Dynasore affects actin assembly and subsequent mammalian embryo development.

\section{Materials and Methods}

\section{Antibodies and chemicals}

Goat polyclonal anti-Dynamin 2 antibody was obtained form Santa Cruz Biotechnology (Santa Cruz, CA, USA), and Dynasore (Catalog number, 324410) was obtained from Calbiochem (Merck KGaA, Darmstadt, Germany). Alexa Fluor rabbit anti-goat 488 was obtained from Invitrogen (Carlsbad, CA, USA). Phalloidin-TRITC was purchased from Sigma-Aldrich (St Louis, MO, USA); we employed $1 \mu \mathrm{g} / \mathrm{ml}$ in the experiment.

\section{Zygote collection and culture}

All animal manipulations were conducted according to the guidelines of the Animal Research Committee of Nanjing Agricultural University, PR China. Mice were housed in a temperature-controlled room with proper light-dark cycles, fed a regular diet, and maintained under the care of the Laboratory Animal Unit, Nanjing Agricultural University, PR China. This study was specifically approved by the Committee of Animal Research Institute, Nanjing Agricultural University, PR China. Forty-eight hours after injection of pregnant mare serum gonadotrophin (PMSG), 6- to 8-week-old ICR mice were injected with human chorionic gonadotrophin (hCG) and immediately mated with male mice. After $18 \mathrm{~h}$, zygotes were collected and cultured 
in $\mathrm{K}$ modified simplex optimized medium (KSOM) (Chemicon, Billerica, MA, USA) covered with paraffin oil at $37 \mathrm{C}$ in a $5 \%$ $\mathrm{CO}_{2}$ atmosphere. Embryos were collected for immunofluorescence staining after different times in culture.

\section{Dynasore treatment}

A $50 \mathrm{mM}$ solution of Dynasore (diluted with DMSO) was diluted with KSOM to $200 \mu \mathrm{M}$. After collection, the mouse embryos were cultured in KSOM medium (the volume of each drop was $50 \mu \mathrm{l}$ in a 35 $\mathrm{mm}$ Corning dish containing $200 \mu \mathrm{M}$ Dynasore for different periods of time to examine the effects of Dynasore on embryo development.

\section{Confocal microscopy}

For immunofluorescence staining, zygotes were fixed in $4 \%$ paraformaldehyde in PBS at room temperature for $30 \mathrm{~min}$ and then transferred to a membrane permeabilization solution ( $0.5 \%$ Triton $\mathrm{X}-100)$ for $20 \mathrm{~min}$. After $1 \mathrm{~h}$ in blocking buffer (1\% BSA in PBS), zygotes were incubated with goat anti-Dynamin 2 (1:25) antibody overnight at $4 \mathrm{C}$. After washing three times ( 2 minutes each time) in wash buffer $(0.1 \%$ Tween 20 and $0.01 \%$ Triton X-100 in PBS), zygotes were labeled with FITC-anti-goat $\operatorname{IgG}(1: 100)$ at room temperature for $1 \mathrm{~h}$. For Phalloidin-TRITC staining, after fixation, permeabilization and blocking as described above, zygotes were incubated with Phalloidin-TRITC $(1 \mu \mathrm{g} / \mathrm{ml})$ for $1 \mathrm{~h}$ and then washed three times ( 2 minutes each time) in wash buffer. The samples were then co-stained with Hoechst $33342(10 \mu \mathrm{g} / \mathrm{ml}$ in PBS $)$ for $10 \mathrm{~min}$. A confocal laser-scanning microscope (Zeiss LSM 700 META, Germany) was employed to examine the samples mounted on glass slides.

Images were taken at 10 (eye lens) $\times 40$ (objective) $\times 1.8$ (scan zoom)-fold magnification in an optical cross section through the center of the oocyte at its largest nuclear diameter. The micrographs were analyzed using the ImageJ 1.44P software (Wayne Rasband, National Institutes of Health, Bethesda, MD, USA), to measure the fluorescence intensity of embryos.

\section{Fluorescence intensity analysis}

Fluorescence intensity statistics were evaluated using the ImageJ (NIH) software. To analyze actin fluorescence intensity, samples of control embryos and treated embryos were mounted on the same glass slide. The ImageJ software was used to define a region of interest (ROI), and the average fluorescence intensity per unit area within the ROI was determined. Independent measurements using identically sized ROIs were made for the cell membrane and cytoplasm. The average values of all measurements were used to compare the final average intensities between control and treated embryos. The intensity curves and the histograms were produced by the ZEN 2009 software (Zeiss, Jena, Germany).

\section{Statistical analysis}

At least three replicates were performed for each experiment, and the results were expressed as means \pm SEM's. Statistical comparisons between groups were made by analysis of variance (ANOVA) followed by Duncan's multiple comparisons test. A P-value of $<$ 0.05 was considered significant. Fluorescence was measured by confocal microscope (Zeiss, LSM 700).

\section{Results}

\section{Disruption of Dynamin 2 arrests mouse early embryonic development}

Before we investigated the role of Dynamin 2 in mouse embryo development, its localization was confirmed by immunofluorescent staining. As shown in Fig. 1A, during the whole process of embryo development, Dynamin accumulated around the periphery of each blastomere. For co-staining of Dynamin 2 and actin, Dynamin 2 showed a localization pattern similar to actin at the periphery of blastomeres (Fig. 1B). To further explore the function of Dynamin 2 in mouse embryonic development, we cultured the embryo at the zygote and 2-cell stage with Dynasore for $24 \mathrm{~h}$, respectively. The results revealed a significant phenomenon: when inhibition began at the zygote stage, none of the zygotes could develop to 2-cell stage (Supplementary Fig. 1A: on-line only). When the inhibition began at the 2-cell stage, the embryos failed to develop to the 4-cell stage: $88 \pm 3 \%(\mathrm{n}=178)$ of the embryos in the control group developed to the 4-cell stage (Fig. 2A) compared with $10 \pm 5 \%(\mathrm{n}=175)$ in the treatment group (Fig. 2B) $(\mathrm{P}<0.05)$. Thus, the results reveal that the Dynamin inhibitor affected mouse early embryo cleavage.

\section{Dynasore treatment causes failure of blastocyst formation}

In mice, compaction begins at the 8-cell stage, and embryos are subjected to morphogenetic changes to prepare for implantation. Since we observed the change in Dynamin 2 localization at the 8-cell stage, we then tested the effect of Dynasore on 8-cell embryo development. After $24 \mathrm{~h}$ culture, we observed the failure of blastocyst formation (Fig. 3A) in the Dynasore-treated embryos; $39 \pm 10 \%$ ( $=$ 88 ) of the embryos in the control group developed to blastocysts or hatched blastocysts, while only $2 \pm 2 \%(n=94)$ developed normally in the treatment group (Fig. 3B) $(\mathrm{P}<0.05)$. Therefore, the results further demonstrate that Dynasore could inhibit mouse morula/ blastocyst formation.

\section{Inhibition of Dynamin 2 activity disrupts the actin filament distribution}

The failure of early embryonic development led us to explore the mechanism during this process. We employed fluorescent staining to observe the dynamics of actin filaments. The results showed that the distribution of actin filaments in the cortex of embryos (2-cell stage) increased significantly in the presence of Dynasore compared with the control embryos, which developed to 4-cell stage (cultured for $24 \mathrm{~h}$, mounted on the same glass) (Fig. 4A). Furthermore, the fluorescent intensity curve (Fig. 4B) and histogram (Fig. 4C) also revealed that the amount of actin in the treatment group was significantly higher than that in the control group. There were no other differences when the embryos were treated with $50 \mu \mathrm{M}$ Dynasore with respect to the actin filaments (Supplementary Fig 1B and C: on-line only). To further confirm this, we cultured the 2-cell embryos for $12 \mathrm{~h}$ (when all of the control embryos and treated embryos remained at the 2-cell stage), and similar results were found in this case: the actin filaments were also enriched in the cortex of Dynasore-treated 2-cell embryos compared with the control embryos (Fig. 4D and E). 


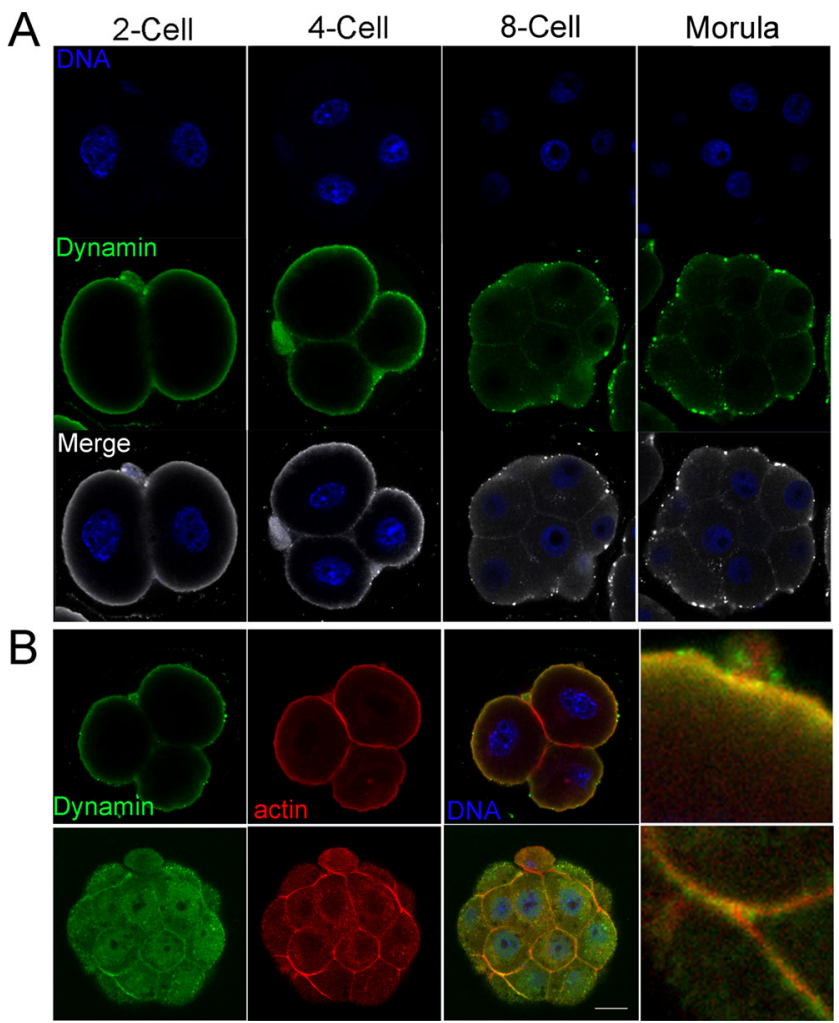

Fig. 1. Dynamin 2 expression and localization in mouse embryos. (A) Dynamin localized at the periphery of blastomeres during the 2-cell, 4-cell, morula and blastocyst stages of mouse embryos. Green, Dynamin 2; blue, chromatin. (B) Co-staining of Dynamin 2 and actin. Dynamin co-localized with actin, and the signals were overlapped. Green, Dynamin 2; blue, chromatin; red, actin; yellow, overlap of green and red. Bar $=20 \mu \mathrm{m}$.

\section{Discussion}

Our previous work confirmed the involvement of Dynamin 2 in meiosis by regulating oocyte polar body extrusion [16]. In the present study, we preliminarily explored the possible function of Dynamin 2 in embryo development. The results demonstrate that the large GTPase Dynamin 2 takes part in embryo cleavage through an actin-based pathway.

We first examined the localization of Dynamin 2 during embryonic development. From the 2-cell to morula stage, Dynamin 2 accumulated at the periphery of blastomeres, and the localization pattern of Dynamin 2 was similar to that of actin. The localization pattern was similar to that in previous work with a somatic cell model and our findings in mouse oocytes $[4,16]$. The special localization of Dynamin 2 prompted us to further explore the possible roles of Dynamin 2 during early embryo development. Inhibition of Dynamin 2 activity with Dynasore caused the failure of embryo cleavage. We cultured embryos from the zygote stage or 2-cell stage, and most of the Dynasore-treated embryos could not develop to the subsequent stage. Also, inhibition of Dynamin 2 from the 8-cell stage caused the failure of compaction. Since compaction of embryos occur at
A

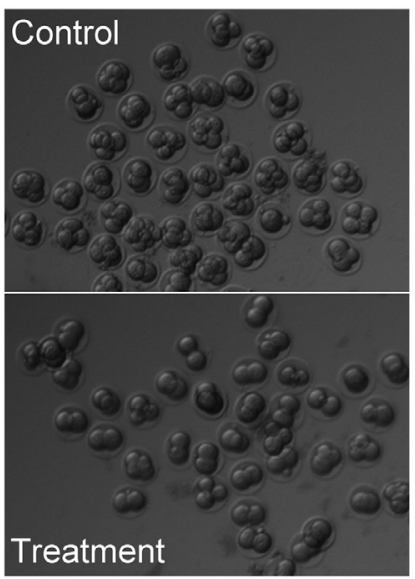

B Rate of 4-Cell after treatment

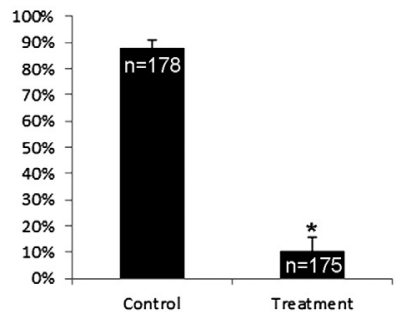

Fig. 2. Effects of the Dynamin 2 inhibitor Dynasore effects early mouse embryo cleavage. (A) After culture in Dynasore for $24 \mathrm{~h}$ at the 2-cell stage, the embryos failed to cleave and arrested at the 2-cell stage, while the control embryos developed to the 4-cell stage. (B) Rate of embryo development after Dynasore treatment. * Significantly different $(\mathrm{P}<0.05)$.
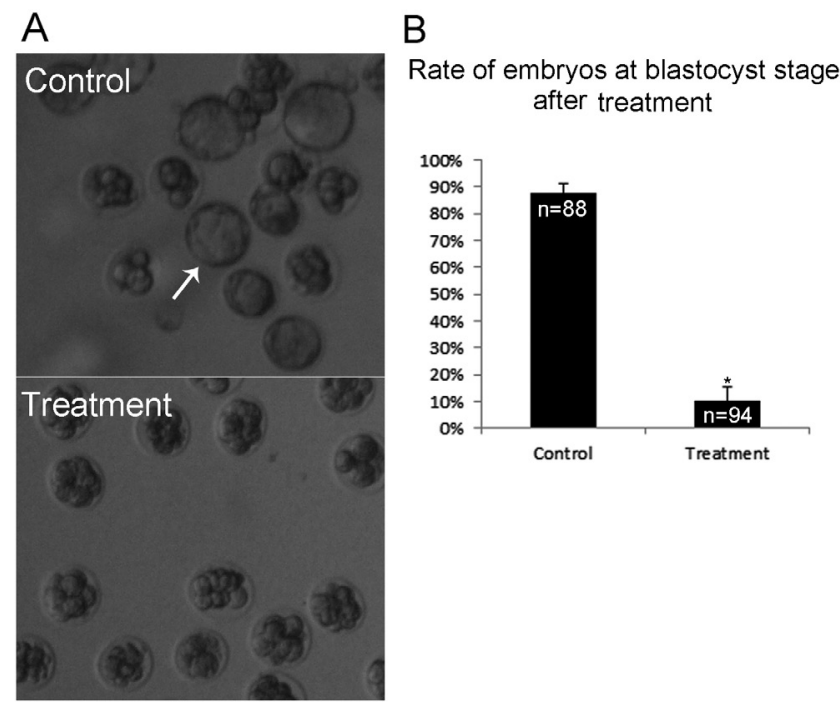

Fig. 3. Effects of the Dynamin 2 inhibitor Dynasore on blastocyst formation during mouse embryo development. (A) After Dynasore treatment at the 8-cell stage, embryos failed to develop to the blastocyst, while the control embryos developed normally to the blastocyst stage (arrow). (B) Rate of blastocyst formation after Dynasore treatment. * Significantly different $(\mathrm{P}<0.05)$.

the 8-cell stage and a previous study demonstrated that molecular disruption of actin prevents embryo compaction [17], we reasoned that the failure of blastocyst formation results from the failure of compaction. Furthermore, previous studies together with our results have proved that Dynamin is required for cytokinesis in cancer cells [18], in zebrafish embryos [19] and in mammalian oocytes maturation $[16,20]$. Thus, we infer that the function of Dynamin 


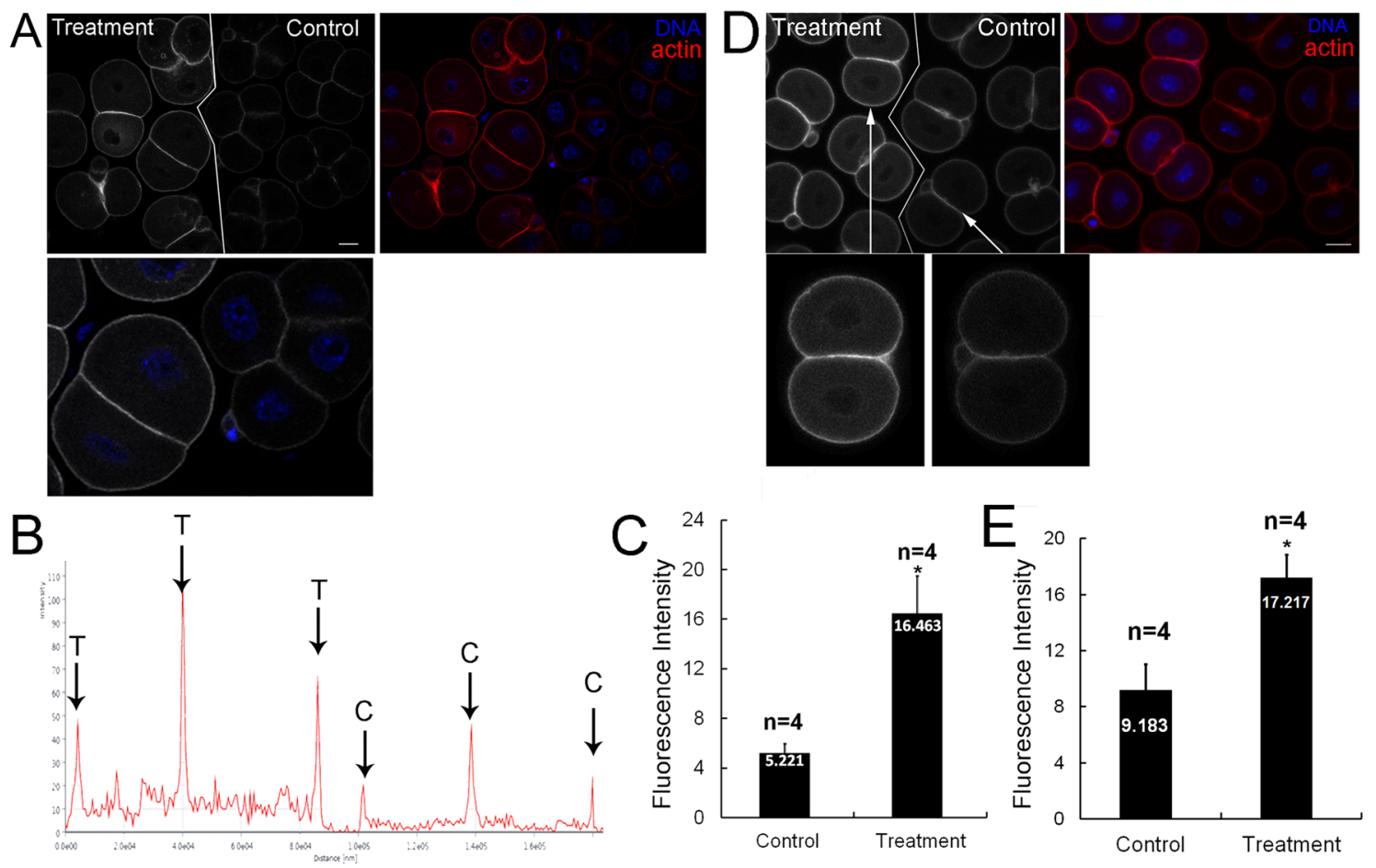

Fig. 4. Changes in actin expression after suppressing Dynamin 2 activity by Dynasore treatment. (A) After culture for $24 \mathrm{~h}$, the control group developed to the 4-cell stage, while the treatment group arrested at the 2-cell stage; its fluorescence signal was also higher than that in the control group. Red, actin; blue, chromatin. Bar=20 $\mu \mathrm{m}$. (B) The fluorescence intensity curve shows a comparison of the actin fluorescence signals of representative embryos for Fig. 4A. The peaks (arrows) indicate the actin signal at the membrane of the blastomere in mouse embryos. C, control; T, treatment. (C) The measurements of the fluorescence intensity of actin after $24 \mathrm{~h}$ of treatment. * Significantly different $(\mathrm{P}<0.05)$. (D) After $12 \mathrm{~h}$ of culture, both the control and treatment group were at the 2-cell stage, and the fluorescence signal of actin in the treatment group was higher than that in the control group. (E) The measurements of the fluorescence intensity of actin after $12 \mathrm{~h}$ of treatment. * Significantly different $(\mathrm{P}<0.05)$. Red, actin; blue, chromatin. Bar $=20 \mu \mathrm{m}$.

in the embryo is conserved and that the failure of embryo cleavage is possibly caused by a deficiency of cytokinesis.

Accumulating work has shown that Dynamin regulates actin polymerization in various models [16, 20-22], which led us to explore the relationship between Dynamin and actin in mouse embryos. The co-localization of Dynamin and actin indicated a relationship between them. This hypothesis was also confirmed in our study, and inhibition of Dynamin by Dynasore caused an aberrant distribution of actin filaments, which was consistent with previous work showing that a low concentration of Dynamin 2 enhanced actin nucleation via Arp2/3 complex and cortactin [23]. Decreased actin assembly as a result of high inhibition of Dyanmin 2 activity is an interesting phenotype and indicates that Dyanmin 2 plays a dynamic and balanced regulatory role in actin assembly and disassembly. Our results, together with those of previous studies, shows a conserved role of Dynamin 2 in actin nucleation or assembly. Therefore, our study reveals that Dynamin regulates mouse embryo cleavage via its effect on the actin filament distribution.

Taken together, our preliminary results indicate that Dynamin 2 is essential for mouse early embryo cleavage, and this regulation might be mediated in an actin-based way.

\section{Acknowledgement}

This work was supported by the Specialized Research Fund for the Doctoral Program of Higher Education of China (20130097120055), and the Biogreen 21 Program (PJ009594, PJ009080 and PJ00909801), RDA, Republic of Korea.

\section{References}

1. Shpetner HS, Vallee RB. Identification of dynamin, a novel mechanochemical enzyme that mediates interactions between microtubules. Cell 1989; 59: 421-432. [Medline] [CrossRef]

2. Mettlen M, Pucadyil T, Ramachandran R, Schmid SL. Dissecting dynamin's role in clathrin-mediated endocytosis. Biochem Soc Trans 2009; 37: 1022-1026. [Medline] [CrossRef]

3. Schafer DA. Regulating actin dynamics at membranes: a focus on dynamin. Traffic 2004; 5: 463-469. [Medline] [CrossRef]

4. Thompson HM, Skop AR, Euteneuer U, Meyer BJ, McNiven MA. The large GTPase dynamin associates with the spindle midzone and is required for cytokinesis. Curr Biol 2002; 12: 2111-2117. [Medline] [CrossRef]

5. Schmid SL, McNiven MA, De Camilli P. Dynamin and its partners: a progress report. Curr Opin Cell Biol 1998; 10: 504-512. [Medline] [CrossRef]

6. Urrutia R, Henley JR, Cook T, McNiven MA. The dynamins: redundant or distinct functions for an expanding family of related GTPases? Proc Natl Acad Sci USA 1997; 94: 377-384. [Medline] [CrossRef]

7. Mears JA, Hinshaw JE. Visualization of dynamins. Methods Cell Biol 2008; 88 237-256. [Medline] [CrossRef] 
8. McNiven MA, Kim L, Krueger EW, Orth JD, Cao H, Wong TW. Regulated interactions between dynamin and the actin-binding protein cortactin modulate cell shape. $J$ Cell Biol 2000; 151: 187-198. [Medline] [CrossRef]

9. Gareus R, Di Nardo A, Rybin V, Witke W. Mouse profilin 2 regulates endocytosis and competes with SH3 ligand binding to dynamin 1. J Biol Chem 2006; 281: 2803-2811. [Medline] [CrossRef]

10. Qualmann B, Roos J, DiGregorio PJ, Kelly RB. Syndapin I, a synaptic dynaminbinding protein that associates with the neural Wiskott-Aldrich syndrome protein. $\mathrm{Mol}$ Biol Cell 1999; 10: 501-513. [Medline] [CrossRef]

11. Lamprecht R. The actin cytoskeleton in memory formation. Prog Neurobiol 2014; 117: 1-19. [Medline] [CrossRef]

12. Sun SC, Sun QY, Kim NH. JMY is required for asymmetric division and cytokinesis in mouse oocytes. Mol Hum Reprod 2011; 17: 296-304. [Medline] [CrossRef]

13. Sun SC, Xu YN, Li YH, Lee SE, Jin YX, Cui XS, Kim NH. WAVE2 regulates meiotic spindle stability, peripheral positioning and polar body emission in mouse oocytes. Cell Cycle 2011; 10: 1853-1860. [Medline] [CrossRef]

14. Sun SC, Wang ZB, Xu YN, Lee SE, Cui XS, Kim NH. Arp2/3 complex regulates asymmetric division and cytokinesis in mouse oocytes. PLoS ONE 2011; 6: e18392. [Medline] [CrossRef]

15. Sun QY, Schatten H. Regulation of dynamic events by microfilaments during oocyte maturation and fertilization. Reproduction 2006; 131: 193-205. [Medline] [CrossRef]

16. Wang QC, Liu J, Wang ZB, Zhang Y, Duan X, Cui XS, Kim NH, Sun SC. Dynamin 2 regulates actin-mediated spindle migration in mouse oocytes. Biol Cell 2014; 106: 193-202. [Medline] [CrossRef]
17. Fierro-González JC, White MD, Silva JC, Plachta N. Cadherin-dependent filopodia control preimplantation embryo compaction. Nat Cell Biol 2013; 15: 1424-1433. [Medline] [CrossRef]

18. Chircop M, Perera S, Mariana A, Lau H, Ma MP, Gilbert J, Jones NC, Gordon CP, Young KA, Morokoff A, Sakoff J, O'Brien TJ, McCluskey A, Robinson PJ. Inhibition of dynamin by dynole 34-2 induces cell death following cytokinesis failure in cancer cells. Mol Cancer Ther 2011; 10: 1553-1562. [Medline] [CrossRef]

19. Feng B, Schwarz H, Jesuthasan S. Furrow-specific endocytosis during cytokinesis of zebrafish blastomeres. Exp Cell Res 2002; 279: 14-20. [Medline] [CrossRef]

20. Zhang Y, Wang QC, Han J, Cao R, Cui XS, Kim NH, Rui R, Sun SC. Involvement of Dynamin 2 in actin-based polar-body extrusion during porcine oocyte maturation. Mol Reprod Dev 2014; 81: 725-734. [Medline]

21. González-Jamett AM, Momboisse F, Guerra MJ, Ory S, Báez-Matus X, Barraza N, Calco V, Houy S, Couve E, Neely A, Martínez AD, Gasman S, Cárdenas AM. Dynamin-2 regulates fusion pore expansion and quantal release through a mechanism that involves actin dynamics in neuroendocrine chromaffin cells. PLoS ONE 2013; 8: e70638. [Medline] [CrossRef]

22. Yamada H, Abe T, Li SA, Tago S, Huang P, Watanabe M, Ikeda S, Ogo N, Asa A, Takei K. N'-[4-(dipropylamino)benzylidene]-2-hydroxybenzohydrazide is a dynamin GTPase inhibitor that suppresses cancer cell migration and invasion by inhibiting actin polymerization. Biochem Biophys Res Commun 2014; 443: 511-517. [Medline] [CrossRef]

23. Schafer DA, Weed SA, Binns D, Karginov AV, Parsons JT, Cooper JA. Dynamin2 and cortactin regulate actin assembly and filament organization. Curr Biol 2002; 12: 1852-1857. [Medline] [CrossRef] 